\title{
Effects of exercise training on depression and anxiety with changing neurotransmitters in methamphetamine long term abusers: A narrative review
}

\author{
Hamid Arazi ${ }^{1}$, Seyedeh Shiva Dadvand ${ }^{1}$, Katsuhiko Suzuki ${ }^{2}$ \\ ${ }^{1}$ Department of Exercise Physiology, Faculty of Sport Sciences, University of Guilan, Rasht, Iran; ${ }^{2}$ Faculty of Sport \\ Sciences, Waseda University, Japan
}

\begin{abstract}
Study aim: It is generally accepted that methamphetamine (MA) is a highly addictive psychostimulant which copies functions of certain neurotransmitters in the brain, and emits dopamine and serotonin in the brain. Frequent abuse of methamphetamine damages dopaminergic and serotonergic nerve endings at different sites of brain and also increases the anxiety and depression. Exercise seems to reverse physiological and neurological damages due to previous MA dependents and help to reduce anxiety and depression in this population. The aim is to determine the effect of exercise training on neurotransmitters and rate of depression and anxiety in chronic methamphetamine abusers based on a literature review.

Materials and methods: The present study investigated published articles in five computerized databases including Magiran, Google scholars, SID, PubMed and Scopus from 2011 until 2020. The searched keywords included sports, neurotransmitter, methamphetamine, depression, anxiety and treatment. The obtained results were described using texts, table and figure.

Results: According to the results, physical activity and exercise significantly increased blood serotonin and dopamine levels and significantly decreased the depression and anxiety.

Conclusion: Different evidences suggested that physical activity and exercise as positive responses and adaptations might influence on circulatory levels of two neurotransmitters (serotonin and dopamine) in methamphetamine addicts, decrease anxiety and depression, and improve preparation in previous MA dependents. In the rehabilitation period, the overall improvement in previous MA dependents might significantly increase. Exercise training can improve the physical and mental state of people addicted to methamphetamine as a non-drug therapy to promote health. However, more research is necessary to support this conclusion.
\end{abstract}

\section{Keywords: Exercise Training - Neurotransmitter - Methamphetamine - Depression - Anxiety - Treatment}

\section{Introduction}

Worldwide, between 14.3 and 52.5 million adults engage in nonmedical use of methamphetamine (MA) and other amphetamine-type stimulants (ATS), second in number only to marijuana users and more than the numbers of heroin and cocaine users combined [35]. Unfortunately, the Methamphetamine use has dramatically increased in many countries in recent years [19].

Methamphetamine causes hormonal and structural brain changes that can lead to risky behavior [42].
Methamphetamine with a complete name, methyl amphetamine, is a powerful central nervous system stimulus that copies functions of certain brain neurotransmitters. Methamphetamine releases dopamine, serotonin and increases levels of glutamate in the brain. Methamphetamine abuse can cause impairment of cognitive functions and damage the nervous system.

Methamphetamine bonds with dopamine, norepinephrine and serotonin neurotransmitters in nerve cells of brain and stimulates the fight-or-flight response through excessive sympathetic nervous system stimulation [4, 9]. Using MA in the short-term MA therefore improves 
productivity, attention-span and energy levels, and may even reduce anxiety [44]. In contrast, however, chronic use depletes dopamine stores in the brain and damages the ability of dopamine and serotonin to bind to their terminals [4].

Depression is a state that greatly affects the quality of personal mood and changes perception of surroundings [12]. It is a state, under which the human is distressed, bored and dull in the long term [25].

Anxiety is a feeling of concern and tension that is provided by a person in response to threatening or stressful situations. Anxiety can be mild or severe to frighten a person. The anxiety is naturally temporary, but if it lasts a long time or continues in the absence of psychological stress or threat, then it should be considered as a problem [25].

Most studies indicate that addicts experience high levels of anxiety, stress and depression and low levels of negative mood regulation [33]. Statham et al. [56] argued that the depression was highly correlated with alcoholism. Prusakowski et al. [43] found that depressed mothers had higher levels of addiction. Compared with the general population, depression symptoms are common in people with drug abuse or dependence. About one third to half of those who have drug abuse or dependence has been diagnosed with major depressive disorder in their life [49].

Pharmacological studies indicate that dopamine and serotonin neurotransmitters and the pathology of anxiety and depression have close relationships, so that the increased release of these neurotransmitters from nerve endings increases anxiety and depression responses in a abusers [46]. The regulation of serotonin in the central nervous system is largely influenced by the re-absorption serotonin pump that plays a major role in treating behavioral disorders such as depression [6]. Reducing serotonin in the brain, causes depression, and in more severe cases leads to Alzheimer's disease [50, 51].

Contrary to previous beliefs, under which physiological and neurological damages by drug were permanent, empirical evidence has indicated that the damage by substance abuse may actually change through exercise $[39,53]$. Aerobic training has been reported to have positive physiological effects on the brain and levels of dopamine and serotonin in patients, who use MA [39, 53] by decreasing pro-inflammatory biomarkers in the circulatory system [28, 39, 54]. Furthermore, it is suggested that the exercise reduces stress, and then anxiety and depression by activating activities of adrenal glands [28]. The present study aimed to determine the effect of exercise training on neurotransmitters and rate of depression and anxiety in chronic methamphetamine abusers based on a literature review.

\section{Materials and methods}

The present study was conducted by searching the texts in Persian and English computerized databases including Magiran, Google scholars, SID, PubMed and Scopus using the keywords of exercise, neurotransmitter, methamphetamine, depression, anxiety and treatment between the years 2011 to 2020 . Titles which were obviously not relevant were disregarded, and titles which seemed vaguely relevant were selected. Duplicate titles were eliminated across database search results.

Exclusion criteria were studies in both human and animal domains in the absence of examining the effectiveness of exercise on the neurotransmitters and the incidence rate of depression and anxiety among the chronic MA abusers. The findings were reported through a full-text review of human and animal research conducted on the effects of various training and physical activities on the neurotransmitters including serotonin and dopamine and the incidence rate of depression and anxiety among the chronic MA abusers.

\section{Results}

According to full survey in prestigious journals, human and animal studies on the effects of exercise training on neurotransmitters and the incidence rate of depression and anxiety among the chronic MA abusers were conducted by researchers between the years 2011 to 2020 .

All studies that did not focus on the effectiveness of exercise training on neurotransmitters and the incidence rate of depression and anxiety in chronic MA abusers were excluded from the study. Based on the findings obtained from a review of studies on the effect of training on neurotransmitters and the incidence rate of depression and anxiety in chronic MA abusers in humans and animals addicted to MA, the physical activities and exercise lead to a significant increase in circulatory serotonin and dopamine levels and significantly reduce the incidence rate of depression and anxiety (Table 1).

\section{Discussion}

Changing the pattern of drug abuse from traditional substances to industrial and chemical drugs and the abuse of stimulants and psychedelics are nowadays serious concerns. Industrial opioids are a combination of traditional drugs with chemicals, such as MA [3]. This stimulant and psychedelic drug affects all systems of the body, especially the central nervous system, and is classified as a neurotoxic 
Table 1. Summary of human and animal studies on the effects of exercise training on neurotransmitters and rate of depression and anxiety in chronic methamphetamine abusers

\begin{tabular}{|c|c|c|c|c|}
\hline $\begin{array}{l}\text { Authors } \\
\text { ( years) }\end{array}$ & Title of study & Subjects & Type of exercise or training & Results \\
\hline $\begin{array}{l}\text { 1. Rawson } \\
\text { et al., } 2015\end{array}$ & $\begin{array}{l}\text { The impact } \\
\text { of exercise on } \\
\text { depression and } \\
\text { anxiety symptoms } \\
\text { among abstinent } \\
\text { methamphetamine- } \\
\text { dependent individuals } \\
\text { in a residential } \\
\text { treatment setting }\end{array}$ & $\begin{array}{l}135 \text { MA- } \\
\text { dependent adults }\end{array}$ & $\begin{array}{l}\text { The exercise intervention consisted of } \\
\text { a progressive aerobic and resistance } \\
\text { exercise training program that was } \\
\text { conducted with participants three } \\
\text { days a week during the } 8 \text {-week trial } \\
\text { (totaling } 24 \text { sessions). Exercise } \\
\text { sessions were about } 55 \text { minutes } \\
\text { in length, structured as follows: } \\
\text { 5-minute warm-up, } 30 \text { minutes of } \\
\text { aerobic activity on a treadmill, } 15 \\
\text { minutes of weight training for the } \\
\text { major muscle groups (arms, chest, } \\
\text { back, and legs) and a 5-minute } \\
\text { cool-down with stretching. Specific } \\
\text { exercise maneuvers engaged in during } \\
\text { the weight training included chest } \\
\text { press, front pull down, leg press, } \\
\text { reverse lunges, calf raises, lateral } \\
\text { raises, bicep curls, and triceps press. } \\
\text { Each session was individual-based, } \\
\text { guided and monitored by a study } \\
\text { staff exercise physiologist. Using } \\
\text { heart rate monitors, the exercise } \\
\text { physiologist worked closely with } \\
\text { each individual participant on training } \\
\text { days to increase treadmill speed/ } \\
\text { slope to maintain a heart rate between } \\
60 \% \text { and } 80 \% \text { of maximum for } 30 \\
\text { minutes. Once a participant was able } \\
\text { to complete two sets of } 15 \text { repetitions } \\
\text { of any given exercise, weight was } \\
\text { incrementally increased. }\end{array}$ & $\begin{array}{l}\text { Analyses indicate a significant } \\
\text { effect of exercise on reducing } \\
\text { depression and anxiety symp- } \\
\text { toms over the 8-week period } \\
\text { compared to a health education } \\
\text { control group. A significant dose } \\
\text { interaction effect between session } \\
\text { attendance and exercise was found } \\
\text { as well on reducing depression } \\
\text { and anxiety over time compared to } \\
\text { the control group. Results support } \\
\text { the role of a structured exercise } \\
\text { program as an effective interven- } \\
\text { tion for improving symptoms of } \\
\text { depression and anxiety associated } \\
\text { with MA abstinence }\end{array}$ \\
\hline $\begin{array}{l}\text { 2. Haglund } \\
\text { et al., } 2015\end{array}$ & $\begin{array}{l}\text { Predictors of } \\
\text { Depression Outcomes } \\
\text { Among Abstinent } \\
\text { Methamphetamine- } \\
\text { Dependent } \\
\text { Individuals Exposed } \\
\text { to an Exercise } \\
\text { Intervention }\end{array}$ & $\begin{array}{l}135 \text { MA- } \\
\text { dependent adults }\end{array}$ & $\begin{array}{l}\text { 8-week progressive aerobic and } \\
\text { resistance exercise training program }\end{array}$ & $\begin{array}{l}\text { Results showed that at the 8-week } \\
\text { trial endpoint, participants ran- } \\
\text { domized to the exercise interven- } \\
\text { tion showed significantly greater } \\
\text { reduction in depression symptom } \\
\text { scores than participants random- } \\
\text { ized to the health education group, } \\
\text { and that participants who attended } \\
\text { the greatest number of exercise } \\
\text { sessions derived the greatest } \\
\text { benefit and exercise in moderate } \\
\text { dose is effective at treating depres- } \\
\text { sive symptoms in individuals in } \\
\text { early recovery from addiction, and } \\
\text { furthermore, that treatment with } \\
\text { exercise appears to be particularly } \\
\text { beneficial to individuals who suf- } \\
\text { fer from severe medical, psychiat- } \\
\text { ric, and addictive disorders }\end{array}$ \\
\hline
\end{tabular}


Table 1. cont.

\begin{tabular}{|c|c|c|c|c|}
\hline $\begin{array}{l}\text { Authors } \\
\text { ( years) }\end{array}$ & Title of study & Subjects & Type of exercise or training & Results \\
\hline $\begin{array}{l}\text { 3. Zhu et al., } \\
2016\end{array}$ & $\begin{array}{l}\text { Beneficial effects } \\
\text { of Tai Chi for } \\
\text { amphetamine-type } \\
\text { stimulant dependence: } \\
\text { a pilot study }\end{array}$ & $\begin{array}{l}\text { Sixty male } \\
\text { subjects with } \\
\text { stimulant } \\
\text { dependence }\end{array}$ & $\begin{array}{l}\text { Sixty male participants were } \\
\text { allocated to the Tai Chi }(\mathrm{n}=30) \text { or } \\
\text { standard care groups }(\mathrm{n}=30) \text { by } \\
\text { administrative staff. They participated } \\
\text { in exercise sessions five times a week } \\
\text { for } 12 \text { consecutive weeks. }\end{array}$ & $\begin{array}{l}\text { The study showed that the relax- } \\
\text { ation in relation to Tai Chi reduced } \\
\text { anxiety and helped people become } \\
\text { more self-aware and internally } \\
\text { focused and Tai Chi is a promising } \\
\text { exercise that improves quality of } \\
\text { life for individuals with stimulant } \\
\text { dependence }\end{array}$ \\
\hline $\begin{array}{l}\text { 4. Damghani } \\
\text { et al., } 2016\end{array}$ & $\begin{array}{l}\text { Swimming } \\
\text { exercise attenuates } \\
\text { psychological } \\
\text { dependence } \\
\text { and voluntary } \\
\text { methamphetamine } \\
\text { consumption in } \\
\text { methamphetamine } \\
\text { withdrawn rats }\end{array}$ & Male Wistar rats & $\begin{array}{l}\text { swimming sessions ( } 45 \mathrm{~min} / \text { day, five } \\
\text { days per week, for } 14 \text { days) }\end{array}$ & $\begin{array}{l}\text { The results showed that regu- } \\
\text { lar swimming exercise reduced } \\
\text { voluntary METH consumption } \\
\text { in animal models of craving by } \\
\text { reducing anxiety, and depression } \\
\text { in the METH-withdrawn rats. } \\
\text { Thus, physical training may be } \\
\text { ameliorating some of the with- } \\
\text { drawal behavioral consequences } \\
\text { of METH }\end{array}$ \\
\hline $\begin{array}{l}\text { 5. Arazi and } \\
\text { Dadvand, } \\
2017\end{array}$ & $\begin{array}{l}\text { The effect of eight } \\
\text { week aerobic } \\
\text { training on plasma } \\
\text { levels of serotonin } \\
\text { and depression in } \\
\text { addicted men to } \\
\text { methamphetamine } \\
\text { during rehabilitation }\end{array}$ & $\begin{array}{l}20 \text { men } \\
\text { addicted to } \\
\text { methamphetamine }\end{array}$ & $\begin{array}{l}8 \text { weeks, } 3 \text { days a week (each session } \\
\text { for } 45 \text { min, included } 10 \text { min of } \\
\text { warm up, running as two times of } \\
15 \text { minutes with an intensity of } 70 \text { - } \\
75 \% \text { of maximum heart rate, resting } \\
\text { intervals of } 3 \text { to } 4 \text { min between them } \\
\text { and } 5 \text { min cool down) }\end{array}$ & $\begin{array}{l}\text { The results of study indicated that } \\
\text { the aerobic training significantly } \\
\text { increased serotonin levels in the } \\
\text { experimental group compared to } \\
\text { control group. The researchers } \\
\text { concluded that aerobic training } \\
\text { can impact on blood levels of } \\
\text { serotonin in addicted men to } \\
\text { methamphetamine and increase } \\
\text { plasma serotonin concentration } \\
\text { and cause remarkable reduction in } \\
\text { depression }\end{array}$ \\
\hline
\end{tabular}

substance [60]. This amphetamine derivative has attracted the attention of most people, especially young people, in recent years due to its stimulatory properties, hallucinations, pleasures and euphoria [20].

The MA abuse as an illness affecting both the brain and the behavior in humans and animals impairs neurotransmitters in the nervous systems, importantly including dopaminergic and serotonergic mechanisms. According to evidence, the main role of MA is to elevate the extracellular level of monoamine neurotransmitters in synaptic clefts [32]. Although the precise MA mechanism for increasing the concentration of these neurotransmitters is still unclear, this substance seems to accelerate the release of serotonin and dopamine from the presynaptic terminals, as well as prevent the reuptake of these neurotransmitters and their accumulation in the synapse clefts. This substance has been shown to inhibit the monoamine oxidase enzyme responsible for the destruction of secreted neurotransmitters, whose inhibition results in the survival of neurotransmitters [26, 58]. Consequently, the synaptic concentration of monoamine neurotransmitters increases in the brain, resulting in brain stimulation, increased mood, invasive and uncontrollable state, and increased physical activity in abuser [27].

Pharmacological studies indicated a close relationship between both dopamine and serotonin neurotransmitters and the pathology of anxiety and depression, so that the increased release of these neurotransmitters from nerve terminals exacerbates anxiety and depression responses in the abuser [46].

Acute MA abuse disturbs various neurotransmitter systems, especially dopamine in the brain, mainly due to increased release of these neurotransmitters from dopaminergic nerve terminals [7]. The MA through various mechanisms causes damage to dopaminergic terminals in different regions of the brain. This drug due to its similar structure with dopamine is introduced into the terminals of dopaminergic neurons by binding to dopamine transporter 
(DAT) and penetrated into the vesicles via molecular vectors. Finally, the intravesicular $\mathrm{pH}$ imbalance causes the release of dopamine into the cellular cytosol. This stimulant through inhibiting monoamine oxidase provides more dopamine.

Based on previous findings, another mechanism involved in the intracellular accumulation of dopamine can be attributed to a decrease in the level of the vesicular monoamine transporter 2 (VMAT2). In addition, reports show that increased activity of the Tyrosine hydroxylase (the rate-limiting enzyme for dopamine biosynthesis) plays a major role in increasing the intracellular dopamine concentration. The function of DAT (as a marker for dopamine terminals) has also been proven in this regard. In fact, these transporters are the key responsible for the removal of dopamine and maintaining its extracellular concentration in amounts less than the intrinsic toxicity of the central nervous system. The MA through reducing DAT activity can reverse the dopamine flow, direct this neurotransmitter towards the synaptic cleft, and prolong the effect of dopamine on its post-synaptic receptors [38, 41].

The MA effects on the serotonergic neurotransmitter system occur through mechanisms similar to those of dopamine. Substance abuse and drug dependence are a major concern in the current world. Psychiatric and drug-induced disorders affecting the brain are interrelated. The most commonly diagnosed psychiatric symptoms associated with substance abuse are antisocial personality disorder, phobia, and other anxiety disorders, depression disorders and psychotic disorders.

One study found that $76 \%$ of men and $65 \%$ of women with a diagnosis of substance abuse or dependence also suffered from a psychiatric problem [24]. One of the areas of sports psychology is the physical activity of patients with depression that can relieve symptoms of some mental disorders such as anxiety and depression [1]. Depression is one of the most commonly diagnosed psychiatric symptoms characterized by depressed mood, sadness, low selfesteem and reluctance to any kind of daily activity and enjoyment. Neurotransmitter disorder has been observed at the synaptic level in depressed patients. In addition to serotonin, norepinephrine and dopamine have a disorder in depressed patients [1].
Improvement of drug-induced injuries in the dopaminergic and serotonergic system through exercise by increasing the antioxidants can have therapeutic effect, since drug use, like amphetamine, leads to an increase in the reaction of oxygen and nitrogen, and damage to monoaminergic terminals [52]. Long-term sports, on the other hand, increase the activity of endogenous antioxidant enzymes [59].

Therefore, aerobic exercise may be effective in increasing serotonin and dopamine. Long-term aerobic exercises increase free plasma tryptophan, which penetrates into the brain cells and causes the synthesis and distribution of serotonin in the bloodstream [39]. Another possible mechanism for increasing serotonin and dopamine is the neurotrophic growth factor (NGF). The aerobic training induces a vascular endothelial growth factor (VEGF), which may help to heal the injuries caused by substance abuse by stimulating angiogenesis and directly affecting the NGF, resulting in the repair of damaged monoaminergic terminals [39].

The reasons for the effect of aerobic training on depression can be attributed to the level of some neurotransmitters such as serotonin, epinephrine, and dopamine in the brain. This training increases the concentration of these neurotransmitters due to stimulation of the sympathetic nervous system [34]. The aerobic training also stimulates the secretion of endorphins, resulting in feelings of comfort, exercise pressure tolerance, excitement and euphoria. On the other hand, the aerobic training direct the attention of a person from negative thoughts towards positive and relaxing ones [47].

Based on recent biological evidence that binds the opioid system to mood and depression [16, 40, 57], it seems logical that a relevant hypothesis should be taken into consideration. In accordance with the "endorphin hypothesis", the exercise causes increased secretion of endogenous opioid peptides in the brain, reduced pain and general euphoria (Figure 1) [8, 13, 17], in turn reducing anxiety and depression $[8,17]$.

According to various studies, the exercise at least activates some of the same systems that are activated by morphine and other opioids, releasing endogenous opioid peptides, especially beta-endorphins, and raising the threshold of pain [31]. Another study has shown that the exercise training can reduce dependency symptoms in addicted

\section{Pituitary Gland}

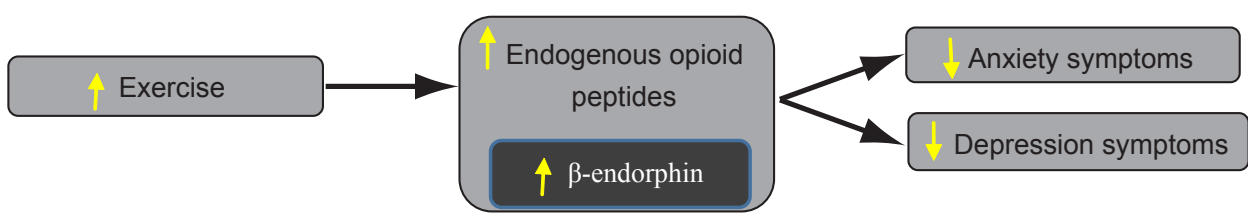

Figure 1. The endorphins hypothesis mechanism 
animals by releasing endogenous opioids through a possible mechanism of downregulated opioid receptor sensitivity [48].

In addition, it has been reported that exercise, in addition to the release of endogenous opioid peptides, especially beta-endorphins, has been implicated by various mechanisms, including neurogenesis, boredom, and mood moderation, in pain relief [55]. Depression and anxiety in MA abusers are the result of the drug's effect on neuropathies; in particular, reducing the binding of dopamine and serotonin makes it impossible to enjoy normally [44]. In addition, MA abuse increases the level of inflammatory markers while reducing blood circulation [44].

On the other hand, the exercise has been proposed to normalize serotonin-dopamine reactions [4], improve circulation and reduce the level of inflammatory biomarkers in the circulatory system [53]. The aerobic training also releases BDNF [21]. The BDNF, a neurotrophin, is responsible for neurogenesis, and reduces the levels of cortisol in the long term $[15,21]$. These changes reduce the level of stress, and subsequently alleviating depression and anxiety [21].

It has been observed that physical activity stimulates BDNF by increasing the mobility-induced neurotransmission. However, physical activity has a more general effect on the brain, which modifies not only serotonin and epinephrine, but also GABA, acetylcholine and dopamine. This effect can explain the reason for the faster treatment response and the absence of side effects of physical activity compared with drug therapy [22]. The exercise can increase the levels of serotonin, norepinephrine and opioids during physical activity, and can reduce depression [14].

Marefat et al. [30] also investigated the effect of yoga practice on anxiety and depression of addicts and reported that physical activity reduced their anxiety and depression and yoga exercises made significant differences in depression and state anxiety level of the experimental group in comparison with the control group, and insignificant difference in trait anxiety level of the experimental group in comparison with the control group. Mogharnasi et al. [37] studied the effects of aerobic exercise training on mental health in addicted women, and highlighted that the aerobic training had an effective role in improving the mental health of addict women.

Miladi-Gorji et al. [36] conducted a research to determine whether morphine-dependent rats would increase the expression of anxiogenic-like behaviours in novel and stressful conditions. The findings showed that Voluntary wheel running reduces anxiety-like behaviors in morphine-dependent and morphine-withdrawn rats. In addition, Brocardo et al. [5] investigating anxiety - and depression-like behaviors are accompanied by an increase in oxidative stress in a rat model of fetal alcohol spectrum disorders: protective effects of voluntary physical exercise and showed that the voluntary wheel running reduces depression and anxiety in adult rats prenatally exposed to ethanol.

Also, Wang et al. [61] examined the impact of physical exercise on substance use disorders and concluded that the moderate and high-intensity aerobic exercises, designed according to the guidelines of American College of Sports Medicine (ACSM), and the mind-body exercises can be an effective and persistent treatment for those with substance use disorders (SUD). Physical exercise can be an effective adjunct treatment method for abstinence from alcohol, nicotine, and illicit drugs in abusers. Physical exercise not only increases the abstinence rate in subjects with SUD, but also eases withdrawal symptoms, anxiety, and depression symptoms. The treatment effects of physical exercise in these four aspects verify that physical exercise guidance by the ACSM is an effective means for drug abstinence. Additionally, mind-body exercises (including Tai Chi Quan, Qigong, and Yoga) have similar treatment effects as to aerobic exercise.

Rawson et al. [45] investigated the impact of exercise on depression and anxiety symptoms among abstinent methamphetamine-dependent individuals in a residential treatment setting and showed that the exercise training significantly reduced symptoms of anxiety and depression in MA non-abusers. Haglund et al. [18] investigating depression outcomes in response to an 8-week exercise intervention among methamphetamine (MA) dependent individuals in early recovery. Their findings exhibited that at the 8-week trial endpoint, participants randomized to the exercise intervention showed significantly greater reduction in depression symptom scores than participants randomized to the health education group, and that participants who attended the greatest number of exercise sessions derived the greatest benefit and exercise in moderate dose is effective at treating depressive symptoms in individuals in early recovery from addiction, and furthermore, that treatment with exercise appears to be particularly beneficial to individuals who suffer from severe medical, psychiatric, and addictive disorders.

Zhu et al. [62] examined the beneficial effects of Tai Chi for amphetamine-type stimulant dependence. The study showed that the relaxation in relation to Tai Chi reduced anxiety and helped people become more selfaware and internally focused and Tai Chi is a promising exercise that improves quality of life for individuals with stimulant dependence. Damghani et al. [11] evaluated the effect of swimming exercise during spontaneous methamphetamine (METH) withdrawal on the anxiety, depression and voluntary METH consumption in METHdependent rats. Their showed that regular swimming exercise reduced voluntary METH consumption in animal models of craving by reducing anxiety, and depression in the METH-withdrawn rats. Thus, physical training may 
be ameliorating some of the withdrawal behavioral consequences of METH.

In another study, Johari et al. [23] examined the effects of aerobic exercise on changes in the level of depression in addicts under methadone treatment was performed. The results of the study showed that aerobic exercise can reduce the level of depression in addicts under methadone treatment. The effects of eight weeks of aerobic training on plasma serotonin levels and the severity of depression in $20 \mathrm{MA}$ abuser men during the rehabilitation period, was investigated by Arazi and Dadvand [2]. The results of study indicated that the aerobic training significantly increased serotonin levels in the experimental group compared to control group. The researchers concluded that aerobic training can impact on blood levels of serotonin in addicted men to methamphetamine and increase plasma serotonin concentration and cause remarkable reduction in depression.

Dadvand and Daryanoosh [10] investigated the effect of an aerobic training period on the serum serotonin and endorphin levels and the severity of depression among 30 addicted women. Their findings exhibited that the aerobic training can increase the serum serotonin and endorphin levels in the experimental group compared to the control group. The results indicated that aerobic training can affect blood levels of serotonin and endorphin and improve the depression in addicted women to drug. Another study was conducted to investigate the effect of tai chi and Qigong exercise on depression and anxiety of individuals with substance use disorders. The findings suggest potentially beneficial effect of Qigong exercise on symptoms of anxiety among individuals with drug abuse Liu et al. [29].

\section{Conclusion}

The findings obtained from the animal and human controlled studies have shown that the physical activities and exercise training can affect the serum levels of serotonin and dopamine neurotransmitters among the MA abusers and reduce anxiety and depression. The exercise training as a non-invasive and non-pharmacological treatment can have a significant effect on mental health promotion due to positive and efficient impacts on the psychological and emotional factors of patients.

Regarding the direct effect of training on the morale of individuals, the psychosocial damaged components of these patients will be significantly improved. In fact, the participation in physical activities makes it possible to stay together with other people in the community, leading to increased life expectancy and reduced depression and anxiety. The exercise training can increase the selfconfidence and empowerment feeling in the patient, increases the sense of usefulness in personal and family life, and enhances daily activities and quality of life. Thus, the MA abusers can use physical activity and exercise training with observance of exercise considerations to elevate the functional level of serotonin and dopamine neurotransmitters and to reduce anxiety and depression during treatment courses.

\section{Conflict of interest: Authors state no conflict of interest.}

\section{References}

1. Allison K.R., Adlaf E.M., Irving H.M., Hatch J.L., Smith T.F., Dwyer J.J., Goodman J. (2005) Relationship of vigorous physical activity to psychologic distress among adolescents. J. Adolesc. Health, 37: 164-166. DOI: 10.1016/j.jadohealth.2004.08.017.

2. Arazi H., Dadvand S.S. (2017) The effect of eight week aerobic training on plasma levels of serotonin and depression in addicted men to methamphetamine during rehabilitation. Alborz Univ. Med. J., 6: 66-74. DOI: http:// aums.abzums.ac.ir/article-1-520-en.html.

3. Ardakani R.K., Nahangi H., Yadegari M., Hosseini-Sharifabad M. (2014) The effects of long-term administration of methamphetamine on the cerebellum of the male mice: a stereological study. Neurosci. J. Shefaye Khatam., 2: $37-45$.

4. Brändle E., Fritzsch G., Greven J. (1992) Affinity of different local anesthetic drugs and catecholamines for the contraluminal transport system for organic cations in proximal tubules of rat kidneys. J. Pharmacol. Exp. Ther, 260: 734-741.

5. Brocardo P.S., Boehme F., Patten A., Cox A., Gil-Mohapel J., Christie B.R. (2012) Anxiety-and depression-like behaviors are accompanied by an increase in oxidative stress in a rat model of fetal alcohol spectrum disorders: Protective effects of voluntary physical exercise. Neuropharmacology, 62: 1607-1618. DOI: 10.1016/j. neuropharm.2011.10.006.

6. Chanrion B., La Cour C.M., Bertaso F., Lerner-Natoli M., Freissmuth M., Millan M.J., Bockaert J., Marin P. (2007) Physical interaction between the serotonin transporter and neuronal nitric oxide synthase underlies reciprocal modulation of their activity. Proc. Natl. Acad. Sci., 104: 8119-8124. DOI: 10.1073/pnas.0610964104.

7. Chiu V.M., Schenk J.O. (2012) Mechanism of action of methamphetamine within the catecholamine and serotonin areas of the central nervous system. Curr. Drug Abuse Rev., 5: 227-242.

8. Cox R.H. (1998) Sport psychology: Concepts and applications (No. Ed. 4). McGraw-hill.

9. Cruickshank C.C., Dyer K.R. (2009) A review of the clinical pharmacology of methamphetamine. Addiction, 104: 1085-1099. DOI: 10.1111/j.1360-0443.2009.02564.x. 
10. Dadvand S.S., Daryanoosh F. (2017) The effect of a period of aerobic training on blood levels of serotonin and endorphin and decreasing depression in addicted women to drug. Daneshvar Medicine: Basic Clin. Res. J., 25: 49-56.

11. Damghani F., Bigdeli I., Miladi-Gorji H., Fadaei A. (2016) Swimming exercise attenuates psychological dependence and voluntary methamphetamine consumption in methamphetamine withdrawn rats. Iranian J. Basic Med. Sci., 19: 594. DOI: 10.22038/IJBMS.2016.7126.

12. Dinas P.C., Koutedakis Y., Flouris A.D. (2011) Effects of exercise and physical activity on depression. Irish J. Med. Sci., 180: 319-325. DOI: 10.1007/s11845-010-0633-9.

13. Dishman R.K., O'Connor P.J. (2009) Lessons in exercise neurobiology: the case of endorphins. Ment. Health Phys. Act., 2: 4-9. DOI: 10.1016/j.mhpa.2009.01.002.

14. Donohue B., Covassin T., Lancer K., Dickens Y., Miller A., Hash A., Genet J. (2004) Examination of psychiatric symptoms in student athletes. J. Gen. Psychol., 131: 29-35. DOI: 10.3200/GENP.131.1.29-35.

15. e Silva T.S., Longui C.A., Rocha M.N., Faria C.D.C., Melo M.R., Faria T.G., de Souza J.A., Rizzo L.V. (2010) Prolonged physical training decreases mRNA levels of glucocorticoid receptor and inflammatory genes. Horm. Res. Paediatr., 74: 6-14. DOI: 10.1159/000313586.

16. Fichna J., Janecka A., Costentin J., Do Rego J.C. (2007) The endomorphin system and its evolving neurophysiological role. Pharmacol. Rev., 59: 88-123. DOI: 10.1124/ pr.59.1.3.

17. Grisel J.E., Bartels J.L., Allen S.A., Turgeon V.L. (2008) Influence of $\beta$-endorphin on anxious behavior in mice: interaction with EtOH. Psychopharmacology, 200: 105-115. DOI: 10.1007/s00213-008-1161-4.

18. Haglund M., Ang A., Mooney L., Gonzales R., Chudzynski J., Cooper C.B., Dolezal B.A., Gitlin M., Rawson R.A. (2015) Predictors of depression outcomes among abstinent methamphetamine-dependent individuals exposed to an exercise intervention. Am. J. Addict., 24: 246-251. DOI: 10.1111/ajad.12175.

19. He J., Xie Y., Tao J., Su H., Wu W., Zou S., ... Zhang X.Y. (2013) Gender differences in socio-demographic and clinical characteristics of methamphetamine inpatients in a Chinese population. Drug Alcohol Depend, 130: 94-100. DOI: 10.1016/j.drugalcdep.2012.10.014.

20. Herman-Stahl M.A., Krebs C.P., Kroutil L.A., Heller D.C. (2006) Risk and protective factors for nonmedical use of prescription stimulants and methamphetamine among adolescents. J. Adolesc. Health, 39: 374-380. DOI: 10.1016/j.jadohealth.2006.01.006.

21. Heyman E., Gamelin F.X., Goekint M., Piscitelli F., Roelands B., Leclair E., Di Marzo V., Meeusen R. (2012) Intense exercise increases circulating endocannabinoid and BDNF levels in humans - possible implications for reward and depression. Psychoneuroendocrinology, 37: 844-851. DOI: 10.1016/j.psyneuen.2011.09.017.

22. Jade Teta N.D., Keoni Teta N.D. (2012) The Exercise Prescription. Textbook of Natural Medicine-E-Book, 36280.

23. Johari A., Hajirasouli M., Golmohammadian M. (2016) Effect of 8 Weeks Aerobic Exercise on Depression's Level of Addicted during Treatment with Methadone. Biol. Forum - An. Int. J., 8: 108-112.

24. Kaplan H.I., Sadock B.J. (1988) Synopsis of psychiatry: Behavioral sciences clinical psychiatry. Williams \& Wilkins Co.

25. Karakoyun-Celik O., Gorken I., Sahin S., Orcin E., Alanyali H., Kinay M. (2010) Depression and anxiety levels in woman under follow-up for breast cancer: relationship to coping with cancer and quality of life. Med. Oncol., 27: 108-113. DOI: 10.1007/s12032-009-9181-4.

26. Killinger B., Shah M., Moszczynska A. (2014) Coadministration of betulinic acid and methamphetamine causes toxicity to dopaminergic and serotonergic nerve terminals in the striatum of late adolescent rats. J. Neurochem., 128: 764-775. DOI: 10.1111/jnc.12496.

27. Kitanaka J., Kitanaka N., Takemura M. (2006) Modification of monoaminergic activity by MAO inhibitors influences methamphetamine actions. Drug Target Insights, 1: 117739280600100001. DOI: 10.1177/117739280600100001.

28. Kohut M.L., McCann D.A., Russell D.W., Konopka D.N., Cunnick J.E., Franke W.D., Castillo M.C., Reighard A.E., Vanderah E. (2006) Aerobic exercise, but not flexibility/ resistance exercise, reduces serum IL-18, CRP, and IL-6 independent of $\beta$-blockers, BMI, and psychosocial factors in older adults. Brain Behav. Immun., 20: 201-209. DOI: 10.1016/j.bbi.2005.12.002.

29. Liu F., Cui J., Liu X., Chen K.W., Chen X., Li R. (2020) The effect of tai chi and Qigong exercise on depression and anxiety of individuals with substance use disorders: a systematic review and meta-analysis. BMC Complement Med. Ther., 20: 1-11. DOI: 10.1186/s12906-02002967-8.

30. Marefat M., Peymanzad H., Alikhajeh Y. (2011) The study of the effects of yoga exercises on addicts' depression and anxiety in rehabilitation period. Procedia Soc. Behav. Sci., 30: 1494-1498. DOI: 10.1016/j.sbspro.2011.10.289.

31. Marghmaleki V.S., Alaei H.A., Malekabadi H.A., Pilehvarian A. (2013) Effect of physical activity on symptoms of morphine addiction in rats, after and before of lesion of the mpfc area. Iranian J. Basic Med. Sci., 16: 1091.

32. Marshall J.F., O'Dell S.J. (2012) Methamphetamine influences on brain and behavior: unsafe at any speed?. Trends Neurosci., 35: 536-545. DOI: 10.1016/j. tins.2012.05.006.

33. Marsiglia F.F., Kulis S., Nieri T., Parsai M. (2005) God forbid! Substance use among religious and nonreli- 
gious youth. Am. J. Orthopsychiatry, 75: 585-598. DOI: 10.1037/0002-9432.75.4.585.

34. Mattson M.P., Duan W., Wan R., Guo Z. (2004) Prophylactic activation of neuroprotective stress response pathways by dietary and behavioral manipulations. NeuroRx., 1: 111-116. DOI: 10.1602/neurorx.1.1.111.

35. Merz F. (2018) United Nations Office on Drugs and Crime: World Drug Report 2017. SIRIUS-Zeitschrift für Strategische Analysen., 2: 85-86.

36. Miladi-Gorji H., Rashidy-Pour A., Fathollahi Y. (2012) Anxiety profile in morphine-dependent and withdrawn rats: effect of voluntary exercise. Physiol. Behav., 105: 195-202. DOI: 10.1016/j.physbeh.2011.08.010.

37. Mogharnasi M., Koushan M., Golestaneh F., Seyedahmadi M., Keavanlou F. (2011) The effect of aerobic training on the mental health of addict women. J. Sabzevar. Univ. Med. Sci., 18: 91-97.

38. Moszczynska A., Callan S.P. (2017) Molecular, behavioral, and physiological consequences of methamphetamine neurotoxicity: implications for treatment. $J$. Pharmacol. Exp. Ther, 362: 474-488. DOI: 10.1124/ jpet.116.238501.

39. O’dell S.J., Galvez B.A., Ball A.J., Marshall J.F. (2012) Running wheel exercise ameliorates methamphetamineinduced damage to dopamine and serotonin terminals. Synapse, 66: 71-80. DOI: 10.1002/syn.20989.

40. Olson G.A., Olson R.D., Vaccarino A.L., Kastin A.J. (1998) Endogenous opiates: 1997. Peptides., 19: 17911843. DOI: 10.1016/S0196-9781(98)00137-5.

41. Panenka W.J., Procyshyn R.M., Lecomte T., MacEwan G.W., Flynn S.W., Honer W.G., Barr A.M. (2013) Methamphetamine use: a comprehensive review of molecular, preclinical and clinical findings. Drug Alcohol Depend., 129: 167-179. DOI: 10.1016/j.drugalcdep.2012.11.016.

42. Pirnia B., Mansour S., Rahmani S., Soleimani A.A. (2015) Sexual behavior and age differences in methamphetamine dependent and non-dependent men who have sex with men (msm). Pract. Clin Psychol., 3: 273-282.

43. Prusakowski M.K., Shofer F.S., Rhodes K.V., Mills A.M. (2011) Effect of depression and psychosocial stressors on cessation self-efficacy in mothers who smoke. Matern Child Health J., 15: 620-626. DOI: 10.1007/s10995-0100640-5.

44. Rau K.S., Birdsall E., Volz T.J., Riordan J.A., Baucum A.J., Adair B.P., Bitter R., Gibb J.W., Hanson G.R., Fleckenstein A.E. (2006) Methamphetamine administration reduces hippocampal vesicular monoamine transporter-2 uptake. J. Pharmacol. Exp. Ther., 318: 676-682. DOI: 10.1124/jpet.105.099200.

45. Rawson R.A., Chudzynski J., Gonzales R., Mooney L., Dickerson D., Ang A., Dolezal B., Cooper C.B. (2015) The impact of exercise on depression and anxiety symptoms among abstinent methamphetamine-dependent indi- viduals in a residential treatment setting. J. Subst. Abuse Treat., 57: 36-40. DOI: 10.1016/j.jsat.2015.04.007.

46. Ressler K.J., Nemeroff C.B. (2000) Role of serotonergic and noradrenergic systems in the pathophysiology of depression and anxiety disorders. Depression Anxiety., 12: 2-19. DOI: 10.1002/1520-6394.

47. Rhodes J.S., Van Praag H., Jeffrey S., Girard I., Mitchell G.S., Garland Jr T., Gage F.H. (2003) Exercise increases hippocampal neurogenesis to high levels but does not improve spatial learning in mice bred for increased voluntary wheel running. Behav. Neurosci., 117: 1006. DOI: 10.1037/0735-7044.117.5.1006.

48. Saadipour K.H., Sarkaki A., Badavi M., Alaei H. (2008) Effect of short-term forced exercise on naloxone induced withdrawal symptoms in morphine addicted male rats. Armaghane-danesh., 12: 73-81.

49. Sadock B.J., Sadock V.A., Levin Z.E. (Eds.). (2007) Kaplan and Sadock's study guide and self-examination review in psychiatry. Lippincott Williams \& Wilkins.

50. Salmon E. (2007) A review of the literature on neuroimaging of serotoninergic function in Alzheimer's disease and related disorders. J. Neural. Transm., 114: 1179-1185. DOI: 10.1007/s00702-007-0636-5.

51. Sauer W.H., Berlin J.A., Kimmel S.E. (2003) Effect of antidepressants and their relative affinity for the serotonin transporter on the risk of myocardial infarction. Circulation., 108: 32-36. DOI: 10.1161/01. CIR.0000079172.43229.CD.

52. Segura-Aguilar J., Kostrzewa R.M. (2004) Neurotoxins and neurotoxic species implicated in neurodegeneration. Neurotox Res., 6: 615-630.

53. Smith A.D., Zigmond M.J. (2003) Can the brain be protected through exercise? Lessons from an animal model of parkinsonism. Exp. Neurol., 184: 31-39. DOI: 10.1016/j. expneurol.2003.08.017.

54. Smith M.A., Lynch W.J. (2012) Exercise as a potential treatment for drug abuse: evidence from preclinical studies. Front Psychiatry., 2: 82. DOI: 10.3389/ fpsyt.2011.00082.

55. Smith M.A., Yancey D.L. (2003) Sensitivity to the effects of opioids in rats with free access to exercise wheels: $\mu$-opioid tolerance and physical dependence. Psychopharmacology, 168: 426-434. DOI: 10.1007/s00213-003-1471-5.

56. Statham D.J., Connor J.P., Kavanagh D.J., Feeney G.F., Young R.M.D., May J., Andrade J. (2011) Measuring alcohol craving: development of the Alcohol Craving Experience questionnaire. Addiction, 106: 1230-1238. DOI: 10.1111/j.1360-0443.2011.03442.x.

57. Stein D.J., van Honk J., Ipser J., Solms M., Panksepp J. (2007) Opioids: from physical pain to the pain of social isolation. CNS Spectrums., 12: 669-674.

58. Suzuki O., Hattori H., Asano M., Oya M., Katsumata Y. (1980) Inhibition of monoamine oxidase by d-metham- 
phetamine. Biochem. Pharmacol., 29: 2071-2073. DOI: 10.1016/0006-2952(80)90493-1.

59. Teixeira A.M., Trevizol F., Colpo G., Garcia S.C., Charão M., Pereira R.P., Fachinetto R., Rocha J.B.T., Bürger, M.E. (2008) Influence of chronic exercise on reserpine-induced oxidative stress in rats: behavioral and antioxidant evaluations. Pharmacol. Biochem. Behav., 88: 465-472. DOI: 10.1016/j.pbb.2007.10.004.

60. Thanos P.K., Kim R., Delis F., Ananth M., Chachati G., Rocco M.J., Masad I., Muniz J.A., Grant S.C., Gold M.S., Cadet J.L., Volkow N.D. (2016) Chronic methamphetamine effects on brain structure and function in rats. PLoS One, 11: e0155457. DOI: 10.1371/journal. pone. 0155457 .

61. Wang D., Wang Y., Wang Y., Li R., Zhou C. (2014) Impact of physical exercise on substance use disorders: a meta-analysis. PLoS One, 9: e110728. DOI: 10.1371/ journal.pone.0110728.
62. Zhu D., Xu D., Dai G., Wang F., Xu X., Zhou D. (2016) Beneficial effects of Tai Chi for amphetamine-type stimulant dependence: A pilot study. Am. J. Drug Alcohol Abuse, 42: 469-478. DOI: 10.3109/00952990.2016.11.

\section{Received 18.03.2021}

Accepted 15.11.2021

(c) University of Physical Education, Warsaw, Poland

Acknowledgments

This publication was made possible by a Grant-in-Aid for MEXT-Supported Program for the Strategic Research Foundation at Private Universities 2015-2019 from the Ministry of Education, Culture, Sports, Science and Technology of Japan (S1511017). 